\title{
Case report: isolated lower lip lesion following cavernoma resection in prone position
}

\author{
Mir Ibrahim Sajid ${ }^{1 *}$ (D), Noor Malik² and Rashid Jooma ${ }^{2}$
}

\begin{abstract}
Background: Surgery in a prone position is necessary when access to posterior anatomical structures is needed. A procedure in this position is associated with complications such as injuries to the eyes, peripheral nerves, and pressure points and swelling of the tongue. We report a rare complication of isolated lower lip swelling following neck dissection in the prone position.

Case presentation: A 25-year-old male patient presented to the clinic with complaint of neck pain for the past 2 months. A cervical spine MRI was done which showed the presence of a cavernoma. C2 laminectomy was performed for resection of the tumor in prone position with the head fixed on a three-point Mayfield clamp. Postoperatively, isolated swelling of the lower lip was observed. The patient was managed conservatively.

Conclusion: Cervical spine surgeries done in prone positions carry an increased risk of postoperative vision loss and swellings including those of the oropharynx and in the periorbital region. Possible risk factors for such conditions include anemia, hypotension, long duration of surgery, and significant intraoperative hydration.
\end{abstract}

Keywords: Isolated lesion, Lower lip, Cavernoma resection, Prone position

\section{Background}

Surgery in a prone position is performed to get access to the posterior anatomical structures such as the spine or the posterior cranial fossa and aids anesthesia by improving oxygenation in patients suffering from acute respiratory distress syndrome (ARDS) [1]. However, prone positioning is associated with complications such as hypoperfusion secondary to hemodynamic changes, ophthalmological disorders, and lesions of both the central and peripheral nervous systems, the latter being primarily due to compression [2].

\section{Case presentation}

We report the case of a 25-year-old male, who presented with complaints of neck pain for the past 2 months with associated left arm weakness and numbness. Magnetic resonance imaging (MRI) with contrast (Fig. 1) was performed at our center which showed a well-demarcated,

\footnotetext{
* Correspondence: ibisajid@gmail.com

${ }^{1}$ Medical College, The Aga Khan University, Stadium Road, Karachi 74880,

Pakistan

Full list of author information is available at the end of the article
}

peripheral T2 hypointense peripheral rim lesion which was most likely representative of a hemosiderin ring. This lesion measured $13.0 \times 7.6 \mathrm{~mm}$ in cranio-caudal and transverse dimensions, and the hemosiderin was seen extending inferiorly into the substance of the spinal cord up to the level of C6-C7 vertebrae. However, no significant perilesional edema was noted on the imaging.

A C2 drilling was done to remove the tumor with the patient positioned in a prone position with his head resting on a Mayfield head holder. Subperiosteal dissection was done from $\mathrm{C} 1$ to $\mathrm{C} 4$ spinal processes, exposing the lamina and the lateral tumor mass. Spinal process of $\mathrm{C} 2$ was drilled using a Cutting Burr 3, and the whole spinal block was removed. After extradural hemostasis was achieved, middle durotomy was performed and the dura was retracted to the left side. Intraoperative suction and crocodile clips were used to excise the space-occupying lesion after which the dura was closed water tight and the wound sutured.

Postoperatively, when the patient was turned into the supine position, an isolated swelling of the lower lip was observed (Fig. 2a, b). On examination, the inflamed 


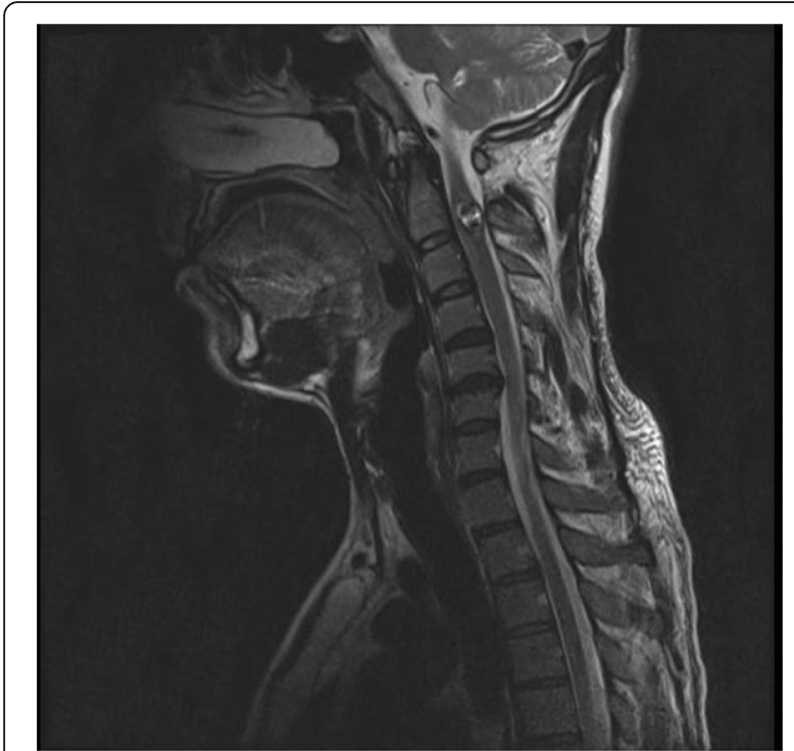

Fig. $1 \mathrm{MRI}$ of the patient showing cavernoma

swelling was between the angles of the mouth. It was non-tender and fluctuant with irregular reddish-white margins. The surface was erythematous with grayish tinge and no discharge. The patient was referred to the maxillofacial department to get a consultation for the swelling. Considering that the lesion could either be a possible drug reaction, a bite during the surgery, or granulomatous disease, the referred physician advised to keep the lips clean and moist and apply Polyfax (Polymyxin B and Bacitracin). The patient recovered well from the neurological symptoms caused by the cavernoma and hence was discharged on analgesics, antiemetics, and anti-histamines. He was advised for followup with the maxillofacial department for treatment of the lesion in case it did not resolve or had discharge. However, 6 days after discharge from the hospital, the swelling subsided with no residual signs of infection or inflammation (Fig. 3).

\section{Discussion}

Many mechanisms have been proposed to justify the complications which arise following surgery done in the prone position. Perioperative vision loss has been associated with ischemic optic neuropathy, central retinal artery occlusion, and cortical blindness, whereas compression of abdomen, restricting blood flow in the inferior vena cava, has been associated with swelling of the epidural and paravertebral venous systems, leading to increased chances of bleeding [2]. Sinha et al. described the swelling of the tongue and pharynx being associated with the use of oral airway, extreme flexion, and dependent head and neck position. Prone positioning for access to the posterior fossa has been documented to

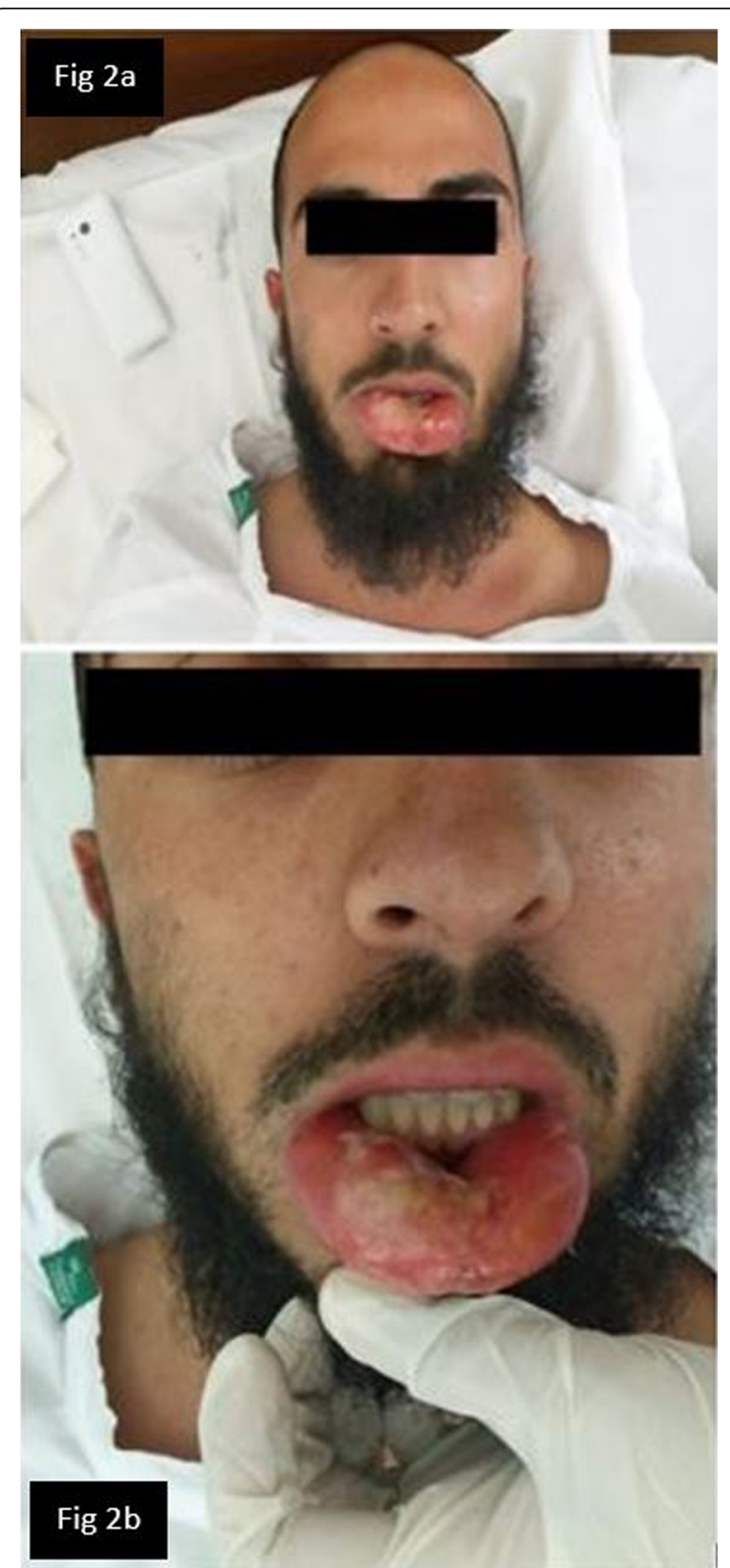

Fig. 2 a, b Isolated lower lip swelling visualized

cause macroglossia, which is attributed to a neurogenic origin [3].

Isolated lower lip swelling has been reported previously [4]. Even with precautionary measures taken to ensure that there was no pressure on eyes, nose, and mouth and that the endotracheal tube was not kinked, George et al. reported a patient who developed lower lip swelling without macroglossia or periorbital edema. This edema and swelling of the oropharyngeal structures have been noticed despite normal intraoperative hemodynamic parameters and oxygen saturation [3]. 


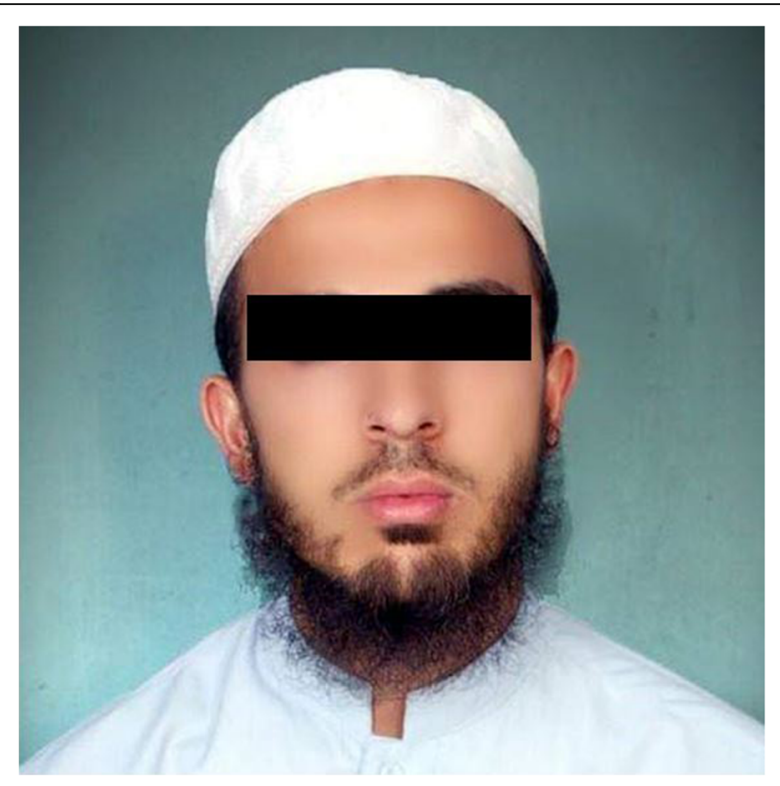

Fig. 3 The swelling subsided with no residual signs of infection or inflammation

The impact of prone position surgery has also remarkably been seen around the periorbital region causing ophthalmological disorders which, in part, are due to compartment syndrome, leading to elevated intraorbital tension. Igal et al. describe such a patient, who developed facial edema and left proptosis with a tight orbit. The octogenarian male had elevated intraocular pressure in the left eye, with complete internal and external ophthalmoplegias [5].

\section{Conclusion}

Cervical spine surgeries done in prone positions carry an increased risk of cardiovascular compromise, postoperative vision loss, increased abdominal pressure, and swellings including those of the oropharynx, tongue, and periorbital region. Possible risk factors for such conditions include anemia, hypotension, long duration of surgery, and significant intraoperative hydration.

\section{Abbreviations}

ARDS: Acute respiratory distress syndrome; MRI: Magnetic resonance imaging

\section{Acknowledgements}

N/A

\section{Authors' contributions}

MIS did the manuscript writing. NM did the manuscript review. RJ did the conception of idea and supervision of the project. All authors read and approved the final manuscript.

\section{Funding}

No funding was obtained for this study.

\section{Availability of data and materials}

The data was obtained from the patient's surgical records and the picture obtained with the consent of the patient.
Ethics approval and consent to participate

The ethics approval has been taken by the Ethics and Review Committee of The Aga Khan University, Karachi, Pakistan, and a copy will be made available on the request of the editor of the journal.

\section{Consent for publication}

Consent has been sought by the patient, and the patient consent form will be made available on the request of the editor of the journal.

\section{Competing interests}

The authors declare that they have no competing interests.

\section{Author details}

${ }^{1}$ Medical College, The Aga Khan University, Stadium Road, Karachi 74880, Pakistan. ${ }^{2}$ Section of Neurosurgery, Department of Surgery, the Aga Khan University Hospital, Karachi, Pakistan.

Received: 30 April 2019 Accepted: 16 September 2019

Published online: 10 October 2019

\section{References}

1. Offner PJ, Haenel JB, Moore EE, Biffl WL, Franciose RJ, Burch JM. Complications of prone ventilation in patients with multisystem trauma with fulminant acute respiratory distress syndrome. J Trauma Acute Care Surg. 2000;48(2):224-8.

2. DePasse JM, Palumbo MA, Haque M, Eberson CP, Daniels AH. Complications associated with prone positioning in elective spinal surgery. World J Orthop. 2015;6(3):351.

3. Sinha A, Agarwal A, Gaur A, Pandey CK. Oropharyngeal swelling and macroglossia after cervical spine surgery in the prone position. J Neurosurg Anesthesiol. 2001;13(3):237-9.

4. George G, Awhad S, Thampi S, Philip M. Isolated lower lip edema: a rare complication of prone positioning. J Anaesthesiol Clin Pharmacol. 2017; 2(33):274-5

5. Leibovitch I, Casson R, Laforest C, Selva D. Ischemic orbital compartment syndrome as a complication of spinal surgery in the prone position. Ophthalmology. 2006;113(1):105-8.

\section{Publisher's Note}

Springer Nature remains neutral with regard to jurisdictional claims in published maps and institutional affiliations.

\section{Submit your manuscript to a SpringerOpen ${ }^{\circ}$ journal and benefit from:}

- Convenient online submission

- Rigorous peer review

- Open access: articles freely available online

- High visibility within the field

- Retaining the copyright to your article

Submit your next manuscript at $\gg$ springeropen.com 